\title{
IDENTITY, STATE, AND TRADITION: A THEORETICAL PERSPECTIVE Ankita Dutta
}

Doctoral Research Scholar, Center for Political Studies, Jawaharlal Nehru University, New Delhi, India. Email: ankita.dutta3@gmail.com

\author{
Article History: Received on $10^{\text {th }}$ March 2020, Revised on $14^{\text {th }}$ April 2020, Published on $21^{\text {st }}$ May 2020
}

\begin{abstract}
Purpose of the Study: This research endeavors to highlight the complex notion of 'identity' and the process of identity formation that involves complex socio-political dynamics that need to be located within the larger socio-cultural spectrum.
\end{abstract}

Methodology: The study is based upon a socio-political and socio-anthropological analysis of the questions of identity, state, tradition, and culture. It has been carried out using relevant theories and concepts borrowed chiefly from the available literature on political sociology and anthropology. It is based on a theorization of the concept of identity as a societal construct and its dynamic relationship with not only the state but also people's traditional beliefs and practices.

Main Findings: Based upon secondary sources, the results of the study showed that 'identity' as a social construct is based on various conflicts and contestations centering around people's diverse identities at one and the same time. Identity politics plays a crucial role in the context of the state machinery, which is not a static entity. It is very much affected by the changes taking place within society, which, in itself, is representative of diversity and heterogeneity. People's traditional beliefs and practices also play a significant role in the formation of identities through institutions recognized as "traditional." They play an important role in reflecting the changing power relations in society through the instrument of law.

Applications of this Study: Both formal state laws and community-backed laws are indispensable in our society because they function within a particular social context that is responsible for the gradual process of internalization of the law and legal processes among people. This, in turn, gets reflected in the formation of various social identities among different groups and communities of people.

Novelty/Originality of this study: This research builds a model to understand the different ways in which institutions recognized as "traditional" create new identities or reinforce the already existing ones vis-à-vis the different stages of political development in a society.

Keywords: Identity, Institutions, Traditional, Namghar, State/Society, Law.

\section{INTRODUCTION}

A democratic political system is based upon fulfilling the demands and aspirations of the people in whom lies the ultimate power of decision-making. Policies and programs aimed at ensuring the welfare of the larger masses are executed through the institution of the state. It exercises power over the society and its people through numerous institutions and processes that eventually become a part of the routine day-to-day lives of the subjects/citizens concerned. The state constantly interacts with people living within its jurisdiction either directly or indirectly through various institutions, organizations and associations. It includes institutions recognized as both formal and informal or traditional. Traditional institutions provide a platform for local communities to respond to and adapt themselves to the changing times and conditions (Sarmah \& Gogoi, 2010). This represents the initial stages of the process of formation of identity within diverse groups, clans, tribes and communities. These institutions provide a platform for these groups and communities of people to not only air their grievances against the higher authorities of the state but also act as a fertile ground for social mobilization around issues of social and political importance. Hence, in this manner, these institutions act as the foundations that enable local communities at the grassroots level to effectively voice their interests and seek concessions from the state in myriad forms, e.g., reservations for socially and economically marginalized and deprived sections of the society.

Accordingly, this study focuses on outlining a theoretical framework of the concept of 'identity' as a social construct. In trying to do this, it seeks to bring out the various contestations and debates around the notion of identity, having varying consequences for the society, its people, and political systems. Here, it takes into account the role of the wider sociopolitical processes, especially traditional structures of a society and institutions recognized as "traditional", which guides the formation of identities within the overall political processes of the state. The findings of this research will be useful in the domains of political sociology and anthropology while working on issues of identity politics in different sociopolitical and cultural contexts and the exercise of the coercive powers of the state through the instrument of law. Bearing this in mind, the study is intended to answer the following research question: What role do traditional institutions play in reflecting the changing power relations in a society that determine the formation of people's identities?

\section{LITERATURE REVIEW}

There are several accounts of the relationship that exists between the state and the society with respect to various institutions and groups that constantly seek to create and re-create new dynamics of power relationships. Different 
writers on the subject have provided different insights on the role of the state in matters of policy and decision-making, while at the same time highlighting its elusiveness and ambiguity in understanding its relationship with the society and vice-versa. State-society distinctions are to be understood in ways that are created internally, which are an aspect of more complex power relations (Migdal, 2009). This necessitates an understanding of the relationship between state and society in historical terms that gave rise to the modern nation-state and the accompanying social order. It was characterized by several new technological innovations that led to the emergence of new methods of organization, surveillance, and control of citizens. All these techniques and methods of modern statecraft have together created the effect of an all-encompassing state structure, which is not only external but also one that stands apart from society (Mitchell, 1991).

The formation of the state is, in itself, a product of a diverse mix of institutions, laws, and policies. The process of interaction between the state and its institutions produces consequences that affect the everyday life of its subjects - the choices they make, the kind of life that they wish to live, the goods they desire to have to make their lives satisfying, etc. (Bhargava \& Acharya, 2008). This engagement of the state takes place through various institutions and groups in society and it is here that we need to understand both the salience of the state in matters of policy and decision-making as well as its elusiveness and ambiguity in understanding its relationship with the society and vice-versa.

Institutions are the foundations of organized socio-political behavior that determine the participants of a particular political arena, shape their various political strategies, and also influence their preferences. The design, structure and functioning of these institutions have far-reaching implications on the overall working of the socio-political system, including the determination of different patterns in the formation of different identities of people (Steinmo, 2001).

Since institutions are socially constructed, they embody shared cultural understandings of society. As such, changes in the specific organizational structure and functioning of institutions do not imply a complete overhaul of the institutional design. It is because institutions are embedded in certain cultural and societal constraints that impose limitations on the efforts of the policymakers to effect any far-reaching changes (Thelen, 1999).

It is through a process of "legibility" that the modern state has imposed order upon those aspects of the society that is needed to understand and control its subjects (Scott, 1998). This is similarly true of different institutions and institutional practices that have adapted themselves to different situations in ways that can be located within a framework of the overarching presence and influence of the state. For instance, the Census reports carried out by state departments are exercises of classification, enumeration, and identification of different groups of people and communities into their castes and sub-castes.

The formation of different institutions, whether modern or traditional, is replete with traces of history that determine the different ways they adapt themselves to different times and circumstances. The laws of the state are often perceived differently by different communities, and especially in a multi-ethnic and diverse country like India, one law may contradict the practices of some communities, while the same might not be true for another community (Mahajan, 2011).

Identity has been defined by Charles Taylor in his book 'The Politics of Recognition' as "something like a person's understanding of who they are, of their fundamental defining characteristics as human beings" (Hall, Rosemary \& Taylor, 1996). The notion of identity has gained enormous attention and popularity in contemporary societies. 'Identity' has developed into a contentious subject, where the fear of losing and asserting one's identity, whether individual or collective, is at the crux of contestations and debates in political theory.

Since identity refers to the idea of how one perceives the self, it is a prescription of who one is, what role one is supposed to enact as a member of the society and citizen of the state, and how one is unique from others in society. The concepts of the 'self' and the 'other' are generally invoked whenever we talk about identity and identity-related issues.

Societies across the globe today are dominated by discourses of identity - a complex web of representing, preserving, or contesting one's identity. In sociological terms, the various traits and characteristics, social relations, roles, and social group memberships that define who one is can be placed within different understandings of identity. Based on diverse social situations and belonging-ness, an individual can have multiple identities. One can have a personal, social, or role identity depending upon the particular context (Dapna, Elmore \& Smith, 2012).

In this context, identity can be either based on a 'relational' web or a 'categorical mode' (Brubaker \& Cooper, 2000). The former defines identity in relation to others (teacher-student, mother-daughter relation), while the latter occurs when people organize themselves in groups or communities based on shared categories such as race, religion, ethnicity, or language.

The overarching nature of the process of globalization has facilitated the transnational flows of commodities and capital and the subsequent growth of supranational political and economic organizations. As a result, similar social and cultural patterns seem to have emerged across different parts of the globe encompassing diverse aspects of people's day-to-day lives. The world has thus now come to be imagined in terms of a single interconnected entity governed by a collective consciousness among its inhabitants of being a part of a global culture that is predominantly 'American' in its values and orientations. 
At the same time, however, contemporary world politics has been marked by the rise of social and political movements across societies that are largely predicated upon a revival of primordial identities and affiliations of individuals and collectivities. Here, globalization does not merely signify the emergence of homogenized cultures, as had been initially speculated by many in the academia (Eriksen, 2007). In reality, it is the other way round, i.e., societies affected by globalization gradually get enmeshed into it with all its accompanying processes, so much so that with time, they come to be characterized by complex and sometimes deeply contentious negotiations related to the issues of identity and identity politics.

There is also a communitarian argument with respect to identity and identity politics in the sense of belonging to one's own community that represents an extension of one's own self and social identity (Kymlicka, 2002). There is a certain socio-economic, cultural, and political environment to which identities of different communities belong. Conflicts in society can be chiefly understood to have arisen due to an imbalance in the socio-economic and power-sharing arrangements between different ethnic identities (Majeed, 2013). In the contemporary times, identity politics in India has become a celebratory expression, considered to be synonymous with the spirit of democratization and an acknowledgment of the pluralism of our polity.

A question that is of utmost relevance to the Indian case is whether primordial groups and traditional institutions such as caste, kinship, ethnicity, and religion are a part of the civil society. Grounded on the modernization theory, the growing literature on civil society today excludes such primordial and traditional groups, regarding them as "pre-civil" (Kaviraj, 1990). Social theorists and sociologists such as Andre Beteille and Dipankar Gupta have argued that traditional communities or ascribed institutions are irreconcilable with the civil society because they are repressive and hierarchical; they represent spheres of unfreedom and are impervious to individual choice.

In his collection of essays, 'Democracy and its Institutions', Andre Beteille argues that a democratic form of government is as good as its institutions. According to him, a democratic system of government reflects the tension between the principles of the 'rule of numbers' and the 'rule of law' (Beteille, 2012). In India, 'constitutional democracy' is being increasingly threatened by 'populist democracy,' wherein the former abides by impersonal legality and the latter gives primacy to the might of numbers and mass mobilizations over the rule of law. He considers civil society as an important set of institutions, ideas, and social arrangements in a democracy that has emerged in the light of distinct historical conditions. He says that the study of institutions, whether classified as formal or informal, is important because they are 'more concrete and tangible as objects of inquiry and investigation' that play a role of crucial importance in the determination of the patterns of formation of different identities of people in society.

Civil society, according to the modernists, refers to only those 'intermediary institutions' that are open and secular in nature and which promote the idea of citizenship. Similarly, Kaviraj has argued that civil society is composed of autonomous individuals capable of making rational and deliberate choices, rather than possessing any intrinsic political attributes. However, to characterize these institutions as partisan and parochial and hence not a part of civil society, is to ignore the fact that civil society is nothing but an organized segment of the society (Oomen, 2010). In India, primordial factors such as religion, caste, ethnicity, and language have been very effectively mobilized in articulating and representing group identities and interests, chiefly with the motive of gaining electoral dividends.

In India, contestations over identity have long been a hallmark of both its pre- and post-colonial polities. This reality was duly recognized by the post-Independent Indian state, which thus found it necessary to address the traditional divisions based on caste, religion, and community existing among diverse sections of the people of the country through a pannational identity. It was because such an identity was based on a due acknowledgment of the internal differences of caste and religion dependent upon narrow and parochial grounds, while at the same time representing an idea of transcending the boundaries beyond such narrow worldviews (Chadha, 2018). This unity-in-diversity approach was reinforced through several ways, e.g., in the commemorations of India's annual Republic Day celebrations, the construction of a policy discourse by the post-Independent Indian state claiming that infrastructural, industrial and scientific development was the ultimate national need and the foremost priority that the state must address, etc.

However, there were certain inherent flaws associated with this unity-in-diversity approach, which Srirupa Roy calls the gap between "paper truths and lived realities, or between procedural commitments and their actual implementation (Roy, 2007). Hence, a variety of sub-national identities could not be eliminated, and they continued to persist, raising their demands on the body-politic from time to time. It was in the 1970s with the appointment of the Second Backward Classes Commission by the Morarji Desai Government under the chairmanship of B.P. Mandal that identity politics based on caste sought to directly pose a challenge to the Nehruvian nationalist project of the post-Independent Indian state.

Commonly speaking, identity politics is the descendant of a Western, individualist ideology where individual identity is conflated with a group identity and hence it is relational. This eventually helps develop common ground between individual and group interests (and rights). It is in this way that the group replaces the individual as the primary center of political discussion, but it does not completely disrupt the discourse of individuality (Gergen, 1999). Rather, the group is treated in much the same way discursively as the individual - imbued with both good and evil intent, held blameworthy, deemed worthy of rights, etc. 
Therefore, the rise of identity politics was a critical reaction to the spirit of Western universalism and its overarching idioms of modernity. The latter overlooked the diverse micro dimensions of Indian society and politics, resulting in a macro versus micro situation in the years that immediately followed after independence.

It was against the pan-Indian nationalism of India that conceived of the Indian nation-state as an invincible and indestructible entity that a counter-theory of sub-nationalism gradually emerged. However, in India, a cohesive, overarching Indian identity has more or less, been highly accommodative of sub-nationalism and people's desire for identifying themselves with their local identities, eventually leading to various political demands made by the people on the state (Basu, 2011).

Advocates of identity politics are now becoming keenly aware of the problematic of separation - because the dominant culture is already prone towards objectification of the "Other," which is forced into identity traps that further confirm the dominant culture's sense of superiority and self-righteousness (Preez, 1980). The existing discourses of oppression, justice, equality, and rights are no doubt important in understanding the diverse traditions within identity politics and activism associated with the same. However, the art of relational politics attempts to develop a new vocabulary, a new consciousness, and a new range of practices that are collaborative and incorporative of identities.

Another perspective on identity has been offered by Prof. Gopal Guru in his work on humiliation - a complex social phenomenon that pervades several spheres of our socio-political life, contexts, and discourses, yet is often absent in our academic analyses. Humiliation rests at the heart of the major problems of modern Indian life - a state based on the western ideas of self and society, and a culture that is based on inherent inequality. For instance, in the West, it is the attitude of race that is the basis of humiliation, and in the East, it is the notion of caste and untouchability that foregrounds the form and content of humiliation (Guru, 2009). The reorganization of modern society was based on the division between the public and the private spheres, which was accompanied by the possibility of misrecognition, degradation and humiliation of people's identities.

A person or a social group who is not only sensitive about self-respect and their identity but can also protest cannot be humiliated. The target of humiliation could be an individual or a group, community, and even an entire country. Bhikhu Parekh gives different examples to show how the re-description of the identity of a person or the entire community can eventually lead to social degradation. According to him, pathological re-description, which is based on race, caste, region or gender, does constitute humiliation of one's identity (Parekh, 2009).

Hence, a general and common trend that is noticeable in the arena of identity politics is to provide an outlet for the expression of grievances related to oppression and deprivation by the marginalized social groups. In this way, it creates a sense of consciousness within the group about their own rights and the restoration of their lost dignity and justice. However, to perceive the horizon of identity politics only in terms of its obvious forms like movements for recognition or identity-based organizations presents only one side of the picture. It is equally important to identify those issues that are or can become potential spaces for the emergence of identity politics but remain outside its purview (Ghosh, 2011). In other words, these are certain areas that can be traced as silent zones of identity politics in the sense that the struggle for identity is yet to germinate there.

Individual identities are understood and imagined with reference to the group/community to which he/she belongs. These identities are continuously shaped, re-shaped, and re-enforced in their interaction with the state and the political narrative that thereby develops, encompassing the interests and concerns of different groups of people at different periods in history.

\section{METHODOLOGY}

This research study is qualitative in nature that has been carried out on the basis of an extensive and in-depth study of the existing literature on identity and identity politics and the role of traditional institutions in determining diverse patterns of the process of identity formation. This has been done through a systematic and descriptive analysis and comparison of works related to the state-society paradox and the eventual formation of identities through a long-drawn and deeplayered process.

The nature of the research is largely theoretical, based on a socio-political and socio-anthropological analysis of the questions of identity, state, tradition, and culture. For this purpose, it has made use of relevant theories and concepts borrowed chiefly from the available literature on political sociology and political anthropology. In order to bring out the multiple facets of traditional institutions and their role in the identity formation of diverse groups and communities, it has largely relied upon secondary sources such as books, academic journals, working papers, periodicals, project reports, etc.

\section{RESULTS/FINDINGS}

States are embedded in societies (Reddy, 2007) and state institutions are enmeshed in the wider array of social and political processes at work. India's public institutions function in the context of a shifting pattern of social demands caused by its experience of a 'long democratic revolution' (Kapur \& Mehta, 2005). 
The results of the study showed that the evolution and development of institutions are determined by conflicts in the particular society of which they are a part as well as within and between the institutions themselves. Institutions perform the functions of allocation of resources and distribution of power in society among various conflicting views and interests. Institutions are, therefore, not homogeneous. Changes in the wider socio-political processes of society exercise a significant influence on the functioning of institutions. This is especially true in the context of a democracy like India, where institutions act as the mechanisms through which the imperatives of governance and the demands of the governed are sought to be reconciled (Pur \& Moore, 2010).

For the purpose of this research, a study of an institution called the Namghar in the North-eastern state of Assam, which is largely understood as a "traditional" institution, was undertaken. The role that such institutions play in the larger politics of the state and determination of the patterns of identity formation brought to light the fact that originally, traditional institutions like the Namghar were generally localized. It was usually restricted to one single village or locality. However, with time, these institutions, as centers of community decision-making, have expanded their administrative sphere to several clusters of villages, not restricted to one single community in many cases.

They play an important role in local governance. The legitimacy and constitutionality of the state and state law, does not undermine their importance in matters of community decision-making. They facilitate the political consciousness of the citizens around identity issues that immediately require the attention of the state. In other words, these institutions, by and large, function as parallel institutions in the state machinery. In many instances, the rulings of the elders associated with these institutions are considered as an exercise of legitimate judicial authority, similar to the effect exercised by state laws over its citizens.

Originally, the Namghar was established in Assam by the saint-reformer Srimanta Sankardeva in the $15^{\text {th }}$ century with a view to providing a platform to facilitate people's participation in village development through local community activities. It served as a refuge for many freedom fighters to seek shelter so as to escape from being caught by the police both during the Indian freedom struggle and the crucial years of the Assam agitation (1979-85) against the issue of illegal, undocumented immigrants residing in the state of Assam. At this time, meetings called mel were regularly held in the Namghars of both Upper and Lower Assam, which helped to mobilize public opinion in favor of protecting the indigenous "Assamese" identity from outside threats $(\mathrm{Neog}, 2008)$. A local volunteer group of both men and women was formed, which extended their help and cooperation in making these meetings a success. Also, during Acharya Vinoba Bhave's Bhoodan Andolan, many activists associated with the movement visited different villages and towns all over Assam and used the institution of the Namghar as a platform to address the needs of the Assamese community (Bhuyan, 2007).

The gradual expansion of the state machinery has gone alongside an expansion of powers of these institutions at the local level. For instance, many political leaders are elected into the state level from the community. These leaders, at times, for their own political gains, may even depend upon the support of these traditional institutions in order to secure funds for the development of public services such as roads, education, water supply, and infrastructure within their respective jurisdictions (Syemlieh, 2006).

During the time of elections, the Namghar too becomes the nerve-center of any political activity, whether in the village, town, or city. It is more so in the villages where issues affecting the daily lives of the common village-folk such as rural banking and timely disbursal of agricultural loans, grants for specific rural development projects, etc. are discussed with much vigor and enthusiasm during the time of panchayat elections. In this way, the Namghar helps to promote overall village development and people's welfare by spreading mass awareness about the different socio-political issues of the day. From time to time, different political parties have utilized the space of the Namghar in order to inform the common masses about their party's election agenda and reforms to be undertaken in the area after coming to power.

We have seen a revival of traditional institutions in a large number of countries of Asia, Africa, and Latin America in recent years. In some places of these countries, governments have formally ceded more authority to such institutions at the local level. Sometimes, the emergence of these institutions has also been the result of a more spontaneous response to the failure of the state to deliver. In the case of India, support for traditional institutions, in most cases, has been a way for politicians to mobilize ethnic, regional, or caste identities. Within the same country, the form of these institutions may vary widely from state to state or village to village and also within states and villages.

\section{DISCUSSION / ANALYSIS}

The anthropological literature on the intricacies of the law and legal processes emphasizes on process models connecting law to various social and cultural structures, to economic and political organizations and to profession or religion. This helps us unravel the implications of the law on different societies and communities at different times and in different contexts. For people who are considered isolated or self-confined and as having institutions that stand independently from other so-called "mainstream" institutions, an anthropological study of the law holds substantive ground (Nader, 2005). According to the process model, the law is not an autonomous domain. It emphasizes the role and importance of power as the key factor in determining the interactions between different users of the law. As a result, disputants are seen as active participants in the process of law-making, employing their own strategies in the entire legal process. Different issues, and not fixed relationships, determine the strategies that disputants employ in the making of the law. Thus, 
according to the process model, power is the central issue in studies of law. This becomes all the more important in contexts of unequal power relations between disputants.

The coexistence of different sources of law can, at times, cause legal conflicts. Sometimes, different and potentially conflicting laws can apply within the same area of jurisprudence. There is a general acceptance today that the cultures and customs of different communities need to be protected. However, the right to self-determination for traditional communities still provides a ground for some of the most wide-ranging disputes around issues of rights, citizenship, and inclusion.

Daily life in itself, is constituted by engagements with the law so much so that it comes to be internalized. Laws play an important role in any society. This holds true of not only formal state laws but also of community-backed laws. Recent works on the anthropology of the state has shifted our attention away from the technologies of modern state power to a question of the effects of this power on people's everyday lives. Even when people choose to engage with the government through 'pure politics' such as street demonstrations, the law itself forces upon them by 'criminalizing' dissent and forcing protesters to deal with issues like bail, release, etc.

Laws structure social identities and vice-versa in a dialectical relationship. For instance, laws that govern village administration coexist with the different understandings that villagers and officials have of particular laws. Notions of customary law also feed into these varied understandings and can be used to make political claims (Chatterjee, 2006).

All laws function within particular contexts and social systems. Power politics played out through the institutional mechanisms of the state determine the strengths and limits that different parties bring in to the debate on the framing and interpretation of laws. Actual knowledge of, or access to the formal state law, is constrained by poverty and ignorance, illiteracy, and bureaucratic opacity. This is clearly brought to light by the fact that despite an emphasis on decentralization and devolution in natural resource management, in legal terms, there has been a continuous centralization and uniform standardization of practices across the country.

The appeal of modern state-backed law is based upon its rationality, uniformity, and lack of bias. All laws, irrespective of whether they are being formulated by the state or local/traditional institutions, include gaps and ambiguities. These are open to a wide range of interpretations by different actors in their struggle over the mores of social conduct, economic resources, and political equality. It remains to be seen, however, as to what, extent, the notions of 'custom' and 'community' generally associated with local traditional institutions provide people with a platform to resist and challenge the centralizing efforts of the state administration. This is where the politics of identity and struggle over identity issues get played out.

Contemporary liberal democracy has become more broad-based with unrepresented issues and challenges now finding support in a larger way. But, the flip side is that the compartmentalization of groups and the coming up of discrete demands prove to be an impediment in the making of a well-knit community in the long-run. It is because of the fact that the rise of sectarianism and the accompanying narratives of identity in the name of caste, religion, tribe, etc. have often unleashed violent conflicts in an already fragmented and diverse society like India.

Lately, societies across the globe have been a witness to various social and political movements predicated upon a revival of and respect for primordial identities and affiliations. This is taking place simultaneously at a time of global restructuring of economies, societies, and institutions across the world on the one hand (Castells, 2006) and reaffirmation of different cultural and group identities on the other.

\section{CONCLUSION}

All institutions make laws. The laws made by an institution may have different meanings for different people in different contexts. People's social conditioning, their relationship with the state, and their understanding of power have implications on the ways they conceive of the content and meaning of different laws. No institution is static. All institutions respond to and adapt themselves to the changing socio-political reality. For any democracy to be effective in responding to people's demands, it needs to tame the power of different institutions in all the three different stages of law-making, law-implementation, and law-adjudication. It is only then that the larger dynamics of law can be understood from the point of view of different institutions, their ways of functioning, and implications on people's lives. Both the state and traditional institutions coexist and continuously interact with one another to create a space for participatory politics to emerge around identity issues that eventually determine the shifting pattern of power relations among different groups and communities in the society. This not only underscores the fact of the salience of the state in matters of policy and decision-making but also its elusiveness in understanding its relationship with the society and vice-versa.

\section{LIMITATION AND STUDY FORWARD}

The nature of this research study on the role of the state and traditional institutions in identity formation is primarily qualitative that has relied mostly on secondary sources. In this sense, it leaves several gaps with respect to understanding and analyzing the role and functions of specific traditional institutions across different states and countries in the politics of identity formation. This area has immense potential to be taken up for further study and research based on a 
comparative analysis of different institutions recognized as "traditional" and their relationship with the state and different groups and communities in the society.

\section{ACKNOWLEDGMENT}

The author is extremely grateful to the library staff of the Central Library of Jawaharlal Nehru University, Delhi, and Omeo Kumar Das Institute of Social Change and Development, Guwahati, Assam. The staff of the North-East Social Science Research Center and Vivekananda Kendra Institute of Culture, both situated in Guwahati, Assam was also immensely cooperative. They extended all possible help to the author in collecting relevant materials and information related to the functioning of the Namghar as a traditional institution in Assam. A special note of thanks to the editorial board of the HSSR journal for providing me with a platform to publish this work.

\section{AUTHOR'S CONTRIBUTION}

As a first step of initiating the study, books on philosophy, religion, society, economy, social geography and anthropology, and other related disciplines were consulted by the author. After this initial stage, relevant materials were collected from various secondary sources like books, research reports and articles in research journals, etc. from various institutions and libraries in Delhi and Assam.

\section{REFERENCES}

1. Ananth Pur, K., \& Moore, M. (2010). Ambiguous Institutions: Traditional Governance and Local Democracy in Rural South India. The Journal of Development Studies, 46(4), 603-623. https://doi.org/10.1080/00220380903002921

2. Basu, Koyel. (2011). Ethnic Conflict and Sub-nationalism in Assam: A Case Study. In Molly Ghosh \& Sutapa Ghosh (Eds.), Questioning Identity: Response of the State and Community in Contemporary India (pp. 59-73). KP Bagchi \& Company.

3. Beteille, Andre. (2012). Democracy and its Institutions. OUP. https://doi.org/10.1093/ac prof:oso/9780198080961.001.0001

4. Bhargava, R., \& Acharya, A. (2008). Political Theory: An Introduction. Pearson Longman.

5. Bhuyan, Abhijit. (2007). Socio-Cultural and Political Role of the Namghar in Assam: A Comparative Study of the Namghars of Borbhogia Village and Bordowa Than/Sattra. Maulana Abul Kalam Azad Institute of Asian Studies.

6. Brubaker, R., \& Cooper, F. (2000). Beyond Identity: Theory and Society. Theory and Society, 29(1), 1-47. https://doi.org/10.1023/A:1007068714468

7. Castells, Manual. (2006). Globalisation and Identity: A Comparative Perspective. Transfer, Journal of Contemporary Culture, XVI(1), 56-65.

8. Chadha, Kalyani. (2018). From Caste to Faith: Contemporary Identity Politics in a Globalised India. Journalism and Communication Monographs, 20(I), 84-87. https://doi.org/10.1177/1522637917750132

9. Chatterjee, Partha. (2006). The Politics of the Governed: Reflections on Popular Politics in Most of the World. Columbia University Press.

10. Dapna, O., Elmore, K., \& Smith, G. (2012). Self, Self-Concept and Identity. In Mark R. Leary \& June Price Tangney (Eds.), Self, Self-Concept and Identity (pp. 27-36). The Guildford Press.

11. Eriksen, Thomas Hylland. (2007). Globalisation: The Key Concepts. Bloomsbury Academic.

12. Gergen, Kenneth J. (1999). Social Construction and the Transformation of Identity Politics. In F. Newman \& L. Holzman (Eds.), End of Knowing: A New Developmental Way of Learning (pp. 1-16). Routledge.

13. Ghosh, Sreemoyee. (2011). Class-Gender Interaction in the Issue of Sexual Harassment of Industrial Informal Women Workers of Durgapur. In Molly Ghosh \& Sutapa Ghosh (Eds.), Questioning Identity: Response of the State and Community in Contemporary India (pp. 92-117). KP Bagchi \& Company.

14. Guru, Gopal. (2009). Humiliation: Claims and Context. Oxford University Press.

15. Hall, Peter A. \& Rosemary, C.R. Taylor. (1996). Political Science and the Three New Institutionalisms. Political Studies, 44(5), 55-83. https://doi.org/10.1111/j.1467-9248.1996.tb00343.x

16. Kapur, D., \& Mehta, P.B. (2007). Public Institutions in India: Performance and Design. OUP.

17. Kaviraj, Sudipta. (1990). On State, Society and Discourse in India. IDS Bulletin, 21(4), 11-18. https://doi.org/10.1111/j.1759-5436.1990.mp21004003.x

18. Kaviraj, Sudipta. (2012). The Trajectories of the Indian State. Permanent Black.

19. Kymlicka, Will. (2001). Politics in the Vernacular: Nationalism, Multiculturalism, and Citizenship. OUP. https://doi.org/10.1093/0199240981.001.0001

20. Kymlicka, Will. (2002). Contemporary Political Philosophy. OUP.

21. Mahajan, Gurpreet. (2011). Accomodating Diversity: Ideas and Institutional Practices. OUP.

22. Majeed, Gulshan. (2013). Ethnicity and Conflict: A Theoretical Perspective. Journal of Political Studies, 20(1), 97-111.

23. Migdal, Joel S. (2009). Studying the State. In Mark Irving Lichbach and Alan S. Zuckerman (Eds.), Comparative Politics, Rationality, Culture and Structure (pp. 231-264). Cambridge University Press. 
24. Mitchell, Timothy. (1991). The Limits of the State: Beyond Statist Approaches and Their Critics. The American Political Science Review, 85(1), 77-96. https://doi.org/10.1017/S0003055400271451

25. Nader, Laura. (2005). The Life of the Law: Anthropological Projects. University of California Press.

26. Neog, Maheswar. (2008). Cultural Heritage of Assam. Omsons Publications.

27. Oomen, T.K.. (2010). Social Movements I: Issues of Identity. OUP.

28. Parekh, Bhikhu. (2009). Logic of Humiliation. In Gopal Guru (Ed.), Humiliation: Claims and Context (pp. 2341). Oxford University Press.

29. Preez, P. du. (1980). The Politics of Identity. St. Martin's Press.

30. Reddy, Sanjay G. (2007). A Rising Tide of Demands India's Public Institutions and the Democratic Revolution. In Devesh Kapur \& Pratap Bhanu Mehta (Eds.), Public Institutions in India: Performance and Design (pp. 168-183). Oxford University Press.

31. Roy, Srirupa. (2007). Beyond Belief: India and the Politics of Post-Colonial Nationalism. Duke University Press. https://doi.org/10.1215/9780822389910

32. Sarmah, A., \& Gogoi, C.F. (2011). Role of Traditional Institutions in Governance: Experience from Karbi Anglong, Assam. Dialogue, 13(2), 76-89. https://doi.org/10.1177/0974354520100209

33. Scott, James C. (1998). Seeing like a State: How Certain Schemes to Improve the Human Condition Have Failed. Yale University Press.

34. Steinmo, Sven. (2001). The New Institutionalism. In Barry Clark \& Joe Foweraker (Eds.), The Encyclopaedia of Democratic Thought (pp. 1-5). Routledge.

35. Syemlieh, David R. (2006). Traditional Institutions of Governance in the Hills of Northeast India: The Khasi Experience. Man and Society: A Journal of Northeast Studies, III(117), 48-61. http://dspace.nehu.ac.i n/handle/1/4902

36. Thelen, Kathleen. (1999). Historical Institutionalism in Comparative Politics. Annual Review Political Science, 8(2), 369-404. https://doi.org/10.1146/annurev.polisci.2.1.369 